\title{
Revista de Estudios Sociales
}

36 | Agosto 2010

Atención psicosocial del sufrimiento en el conflicto armado: lecciones aprendidas

\section{Trauma, duelo, reparación y memoria}

Trauma, Grief, Reparation and Memory

Trauma, duelo, reparação e memória

\section{Elizabeth Lira}

\section{OpenEdition \\ Journals}

\section{Edición electrónica}

URL: https://journals.openedition.org/revestudsoc/13104

ISSN: 1900-5180

Editor

Universidad de los Andes

\section{Edición impresa}

Fecha de publicación: 1 agosto 2010

Paginación: 14-28

ISSN: 0123-885X

\section{Referencia electrónica}

Elizabeth Lira, «Trauma, duelo, reparación y memoria», Revista de Estudios Sociales [En línea], 36| Agosto 2010, Publicado el 01 agosto 2010, consultado el 04 mayo 2021. URL: http:// journals.openedition.org/revestudsoc/13104

\section{(c) (i)}

Los contenidos de la Revista de Estudios Sociales están editados bajo la licencia Creative Commons Attribution 4.0 International. 


\section{Trauma, duelo, reparación y memoria*}

\section{por Elizabeth Lira**}

Fecha de recepción: 16 de diciembre de 2009

Fecha de aceptación: 11 de junio de 2010

Fecha de modificación 30 de junio de 2010

\section{RESUMEN}

El artículo describe y reflexiona acerca de la experiencia de trabajo psicosocial y terapéutico realizado con víctimas de violaciones de Derechos Humanos durante el régimen militar en Chile (1973-1990). Esta experiencia contribuyó a la inclusión de la atención médica y psicológica en las políticas de reparación del Estado a partir de 1990. La evolución de las modalidades terapéuticas y de intervención psicosocial se analizan a la luz de las tareas y dilemas que emergen en el contexto de la transición política: el reconocimiento y reparación de las víctimas, la verdad o la ocultación de los crímenes, la justicia versus la impunidad; el olvido o diferentes formas de memoria y su impacto en las víctimas y en el proceso de reconciliación política.

PALABRAS CLAVE:

Trauma, duelo, reparación, verdad, impunidad, justicia, olvido, memoria.

\section{Trauma, Grief, Reparation and Memory}

\section{ABSTRACT}

The article describes and reflects on the experience of psychosocial and therapeutic work carried out with victims of human rights violations during the military regime in Chile (1973-1990). This experience contributed to the inclusion of medical and psychological care in the State reparation policies since 1990. The evolution in the modes of treatment and psychosocial intervention are discussed in the light of the tasks and dilemmas which emerge in the context of political transition: recognition of and redress for victims, the truth or concealment of crimes, justice versus impunity; oblivion or different forms of memory and their impact on the lives of the victims and on the political reconciliation process.

\section{KEY WORDS:}

Trauma, Grief, Reparation, Impunity, Justice, Forgetfulness, Memory.

\section{Trauma, duelo, reparação e memória}

\section{RESUMO}

O artigo descreve e reflete sobre a experiência do trabalho psicossocial e terapêutico realizado com vítimas de violações de Direitos Humanos durante o regime militar no Chile (1973-1990). Essa experiência contribuiu para a inclusão da assistência médica e psicológica nas políticas de reparação do Estado a partir de 1990. A evolução das modalidades terapêuticas e de intervenção psicossocial são analisadas à luz das tarefas e dilemas que emergem no contexto da transição política: o reconhecimento e reparação das vítimas, a verdade ou a ocultação dos crimes, a justiça versus a impunidade; o esquecimento ou diferentes formas de memória e seu impacto nas vítimas e no processo de reconciliação política.

\section{PALABRAS CHAVE:}

Trauma, duelo, reparação, verdade, impunidade, justiça, esquecimento, memória.

* La investigación para este artículo ha sido realizada en el marco del proyecto "Memoria y Justicia" patrocinado por la Fundación Ford en la Universidad Alberto Hurtado.

** Psicóloga Terapeuta Familiar, Magister en Ciencias del Desarrollo. Directora del Centro de Ética, Universidad Alberto Hurtado, Santiago, Chile. Entre sus publicaciones más recientes se encuentran: Psicología, ética y seguridad nacional: el rol de los psicólogos. Psykhe 17, No. 2: 5-17, 2010; y Chile: dilemas de la memoria política. En Políticas Públicas de la Memòria I Coloquio Internacional Memorial Democràtic Barcelona, eds. Jordi Guixé Coromines y Montserrat Iniesta, 39-83. Barcelona: Editorial Milenio - Memorial Democratic, 2010. Correo electrónico: elira@uahurtado.cl. 
as transiciones políticas desde dictaduras o guerras civiles a regímenes democráticos suelen empezar con países divididos y cargados de un pasado que sigue siendo presente para un gran número de personas, por cuanto sus vidas han estado cruzadas por el conflicto y sus consecuencias. Con frecuencia se hacen llamados a la reconciliación en nombre de la patria común, invitando a superar el pasado conflictivo. Pero los desplazados, los que perdieron a sus familiares que fueron secuestrados, desaparecieron o fueron asesinados, los niños que no tuvieron infancia y que vivieron bajo la amenaza y el miedo no siempre pueden dar vuelta a la página para empezar de nuevo como si no hubiera pasado nada. Los procesos de reconciliación política suelen recurrir a leyes de amnistía que buscan instalar el olvido jurídico y político sobre las responsabilidades criminales ocurridas en un pasado que se resiste a pasar al olvido y que suele convertirse en un presente asfixiado de exigencias y contradicciones para muchos. Por otra parte, la proclamación del olvido como fundamento de la paz social no tiene en cuenta el efecto del conflicto sobre las víctimas e impone, de diversas maneras, una resignación forzosa ante los hechos consumados y a la impunidad subsecuente. Diversas voces han señalado que tanta violencia no puede pasar por la historia como si no hubiera sucedido nada y que la reconciliación requiere hacerse cargo del pasado y reconocer y reparar a las víctimas, incorporando sus memorias y la memoria de la lucha, mediante condiciones de justicia y equidad como ejes de la construcción democrática actual y futura. Emerge así una lucha de visiones y de interpretaciones del pasado y de los procedimientos necesarios para superar sus consecuencias, que coexisten conflictivamente en los espacios políticos de transición. ¿Cómo entender la reconciliación política? ¿Puede ser posible basar la reconciliación política en el reconocimiento de los derechos de todos o es imperativo fundar la paz en la impunidad sobre el pasado?

La prolongación de la violencia por años o décadas genera acostumbramiento. Paradójicamente, la denuncia que se repite una y otra vez contribuye a que, para la mayoría de esa sociedad, esos horrores se vuelvan invisibles y que el trauma y el sufrimiento se transformen en un asunto privado de las víctimas. Cuando las violaciones de Derechos Humanos se tratan políticamente como si no hubiesen existido o, de haber existido, como el costo necesario de la paz, es como si estas sociedades se convirtieran metafóricamente en sociedades ciegas, sordas y mudas al dolor y al horror, donde las voces no resuenan porque no hay nadie que escuche. La mudez y la sordera parecen provenir del miedo. El miedo a la muerte asociado a la violencia que se transforma en un miedo generalizado e inespecífico de muchos, a veces de casi todos, dependiendo de su lugar dentro de la sociedad. El miedo los (nos) hace o nos haría cómplices de esta mudez y sordera y de los hechos que las provocan. En una sociedad con torturados, muertos y desaparecidos, de alguna manera casi todos han (hemos) sido afectados por el terror causado por las amenazas de muerte que circulan en la sociedad. Un sector, casi siempre minoritario, reacciona moralmente con una fuerte indignación ante la denuncia de las violaciones a los derechos de las personas, buscando incidir en la voluntad de terminar con dichas violaciones y producir cambios políticos. Pero en casi todas las sociedades existe un sector importante que ha respaldado la política represiva y se ha identificado con el proceder de las autoridades, valorando sus actuaciones como actos necesarios en defensa del bien común.

El final del conflicto implica hacerse cargo de las tensiones surgidas de estas distintas visiones, establecer el imperio de la ley y el reconocimiento de los derechos de todos, garantizando mediante condiciones legales, culturales y políticas que estos hechos no se repetirán. No obstante, las razones profundas por las cuales la violencia llegó a ocurrir entre nosotros suscitan más polémica que la situación misma. Hay muchos elementos que provienen de raíces históricas y políticas sobre las cuales no hay todavía (y tal vez nunca habrá) un consenso nacional. Por eso la tarea de establecer la paz toma tantos o más años que los que fueron necesarios para generar las condiciones del conflicto, y, quizás, los años necesarios para producir este proceso de comprensión tomarán más tiempo que el resto de nuestras vidas.

Cada sociedad ha debido enfrentar el conflicto y sus consecuencias desde su historia y condiciones políticas, con los valores y principios y visiones políticas de su gente, con su capacidad de forjar dimensiones de responsabilidad compartida sobre el futuro, con el fin de detener la multiplicación de las víctimas y hacerse cargo de éstas. En algunos países se desarrollaron esfuerzos de solidaridad, apoyo y reparación de las víctimas, a pesar de que el conflicto no había terminado, sirviendo de base a políticas oficiales posteriores. En otros, aunque el conflicto se dio por terminado, las medidas de reconocimiento y reparación respondieron a iniciativas oficiales débiles y ambiguas. En todos los casos, las personas afectadas 
por la violencia de las dictaduras y los conflictos armados han visto profundamente alteradas sus vidas, con graves consecuencias. En varios países los profesionales de salud mental se preocuparon por las víctimas desde instituciones solidarias o a título personal. Esos profesionales funcionaron como "delegados" (informales) de la sociedad, asumiendo la responsabilidad de trabajar con las víctimas desde sus saberes y competencias, pero también desde las limitaciones de su rol y ubicación social, que, casi siempre, era, a pesar de todo, marginal. En algunos países la reparación ha sido una política pública que incorporó servicios de salud mental. En ese contexto, los agentes de salud mental se constituyeron en "delegados" formales de la sociedad, como en el caso del Programa de Reparación Integral de Salud (PRAIS) para las víctimas de las violaciones de Derechos Humanos ocurridas en Chile entre 1973 y 1990 (ILAS 1994, 1997). Este programa fue creado acogiendo las recomendaciones de la Comisión de Verdad y Reconciliación (Lira y Loveman 2005).

En este artículo se reflexiona acerca de la experiencia de trabajo psicosocial y terapéutico efectuado en Chile durante el régimen militar (1973-1990) y lo que hemos aprendido en ese trabajo como profesionales de salud mental y como ciudadanos y ciudadanas comprometidos con la paz social y el respeto de los Derechos Humanos.

\section{LAS DEMANDAS DE LAS VÍCTIMAS: VERDAD, JUSTICIA y REPARACIÓN}

Las víctimas han reclamado esclarecer lo que les ha ocurrido a ellas y a sus familiares exigiendo la verdad. Parte de la verdad general y particular se alcanza en las comisiones de la verdad al establecer los hechos sucedidos y los nombres de las víctimas. En los tribunales de justicia, la verdad judicial es particular y posibilita identificar las circunstancias en que ocurrieron los hechos, las víctimas y los responsables en cada caso. La verdad que falta, casi siempre, es la verdad de los sufrimientos, de los temores y sueños de las víctimas y la conexión de sus vidas con la historia de violencia, del conflicto y de la resistencia en el país, permitiendo identificar los significados que estas experiencias han tenido y tienen para ellas.

Las víctimas han reclamado justicia ante los tribunales, con resultados variables, casi siempre precarios. En la mayoría de los casos, los procesos judiciales han demorado décadas en lograr el esclarecimiento de los crímenes que las afectan. En algunos casos, el castigo a los responsables llega muy tarde; los perpetradores son ancianos mentalmente deteriorados y, para más de uno, el pasado y el presente se han borrado de su mente, perdiendo sentido toda acción de justicia. Otros han sido sentenciados como culpables, pero insisten en haber salvado a la patria de sus enemigos y afirman que, de verse enfrentados nuevamente a situaciones semejantes, procederían de la misma forma. No obstante, y a pesar de todas esas limitaciones, la justicia puede desempeñar un rol político pacificador e inhibir las venganzas y la justicia por mano propia. Puede cumplir también un rol terapéutico al confirmar la experiencia de las víctimas (que ha sido negada por décadas), cuando el juez define como delito el atropello y la injusticia sufridos por las personas, ordena el castigo de los perpetradores y determina medidas de reparación.

La no sanción de los crímenes es una forma de negación de que se trata de crímenes. A veces la negación es anterior a la instancia judicial. Ocurre cuando una autoridad declara que tales hechos nunca sucedieron. De esas formulaciones hay numerosos ejemplos. También se observa cuando se reivindican los hechos como actos necesarios en nombre del bien común, lo que constituye una re-negación del sentido que tiene para quienes fueron afectados por ellos. Esta posición favorece la perpetuación de los resentimientos, puede estimular las venganzas y reeditar el conflicto. El equipo de asistencia psicológica de CELS en Argentina señaló hace ya 20 años que "la vigencia de la impunidad en democracia evoca el terror impuesto $[. .$.$] y, por consiguiente$ reaparece la parálisis, la fragmentación, la marginación económico social, el silencio, el miedo, la dificultad de organizarse, de imaginar un proyecto" (CELS 1989; ILAS 1989). Esa situación parece forzar a las víctimas a asumir el daño experimentado, la exclusión y el abuso como si no hubiese responsables y como si el Estado no tuviera la responsabilidad de restablecer el orden y el imperio de la ley, es decir, de garantizar el reconocimiento de los derechos de todos. Si estas situaciones se mantienen, las víctimas pueden sumirse en el desamparo, la desolación y el aislamiento o seguir reclamando sus derechos sin tregua y hasta su muerte, intentando resistir la privatización de las consecuencias de la violencia, devolviéndolas una y otra vez al espacio público y político en el que ocurrieron, denunciando que fueron actos abusivos de agentes del Estado.

Cuando las autoridades se hacen cargo efectivamente de la verdad y la reparación como política de Estado, y de garantizar el ejercicio independiente de la justicia, 
las víctimas pueden recuperar su libertad como ciudadanos, para dejar estas tareas en manos del Estado, de la sociedad civil, o continuar activamente en ellas, si así lo deciden, pero sin la presión moral de tener que desempeñar el rol de voceros incansables de la injusticia y el abuso de sus seres queridos y de ellas mismas.

La reparación es un proceso. La indemnización por el daño causado o una placa en memoria de una o más personas pueden formar parte de medidas de reparación. Pero la reparación social se funda, en primer lugar, en el reconocimiento de que los hechos ocurrieron efectivamente y que constituyeron una injusticia y un abuso, al violarse derechos fundamentales de las personas y las comunidades. La reparación opera mediante un cambio en la actitud social y cívica de las autoridades al asumir la responsabilidad por lo sucedido y sus consecuencias, mediante gestos simbólicos y acciones directas, y cuyo propósito es desagraviar y resarcir esos agravios y daños identificados. ¿Qué medidas y acciones forman parte de las políticas de reparación por parte del Estado en cada circunstancia? ¿Qué es lo que hace o puede hacer la sociedad civil? ¿Qué es lo que las víctimas identifican, requieren y demandan como reparación? Parece obvio que la reparación no se agota en la verdad ni en la sanción judicial de los responsables, pero ambos elementos forman parte del proceso que conduce a la percepción de las víctimas de sentirse reparadas, no obstante considerar que las experiencias y las pérdidas vividas son por definición irreparables.

La reparación se funda en el reconocimiento de las víctimas y de sus derechos; en la afirmación de que a causa de los atropellos han experimentado daños y sufrido diversas consecuencias en sus cuerpos y mentes que han llegado a afectar gravemente a sus familias, sus vínculos cercanos, y la vida de la comunidad a la que pertenecen. El trabajo terapéutico y psicosocial forma parte del proceso de reparación. Se basa en la recuperación de los recursos propios de las personas para reconquistar su condición de sujetos activos y participativos, de ciudadanas y ciudadanos con derechos. La reparación, en su dimensión moral y subjetiva supone que las víctimas pueden tramitar procesos de elaboración y discernimiento que permitan asumir lo vivido como parte de su propia historia, y, al mismo tiempo, moverse del lugar de víctimas, recuperando su autonomía personal. Por su parte, la doctrina de Derechos Humanos señala como estrategias principales de las políticas de reparación asegurar formas de restauración, rehabilitación, compensación e indemnización a las víctimas por los daños causados (Comisión de Derechos Humanos,
ONU 2003). Las intervenciones psicosociales y terapéuticas se inscriben en esos valores y forman parte de esas estrategias.

\section{LO QUE HEMOS APRENDIDO}

Las violaciones de Derechos Humanos tuvieron lugar en Chile como consecuencia de la intervención militar en 1973. Las Fuerzas Armadas derrocaron al gobierno democráticamente elegido que encabezaba Salvador Allende como presidente de la República, apoyado por la Unidad Popular, coalición política de izquierda que llevaba a cabo un proyecto de "transición al socialismo". El Presidente se suicidó en el Palacio de Gobierno el 11 de septiembre y el régimen militar se instaló con muy poca resistencia, controlando completamente el país antes de terminar el día. En pocas horas miles de personas fueron detenidas y sometidas a torturas en más de 1.200 recintos a lo largo del país. Se declaró el estado de sitio, entendido como estado de guerra, y se instalaron consejos de guerra para procesar a los detenidos. Miles de personas fueron ejecutadas como resultado de juicios sumarísimos; otras tantas murieron como consecuencia de las torturas. Miles de ellas recibieron condenas de cárcel; otras fueron expulsadas del país. Los partidarios del gobierno derrocado fueron catalogados y tratados como "enemigos" de la patria (Comisión Nacional de Verdad y Reconciliación 1991; Comisión Nacional de Prisión Política y Tortura 2004).

La asistencia legal, social, médica y psicológica a las personas perseguidas se organizó a inicios de octubre de 1973 con el respaldo de las iglesias, en particular, de la Iglesia católica. ${ }^{1}$ Los abogados que iniciaron la defensa de las personas ante los tribunales de justicia identificaron la necesidad de apoyo y acompañamiento psicosocial de las víctimas y sus familias, y recomendaron que se buscaran formas de atención psicológica porque su estado mental parecía gravemente alterado. Algunos profesionales se acercaron a los organismos solidarios y ofrecieron sus servicios en los organismos de Derechos Humanos. Otros ofrecieron horas de atención en sus consultas privadas. Algunos años después, se organizó formalmente la atención psicológica en los organismos de Derechos Humanos, en la Vicaría de la Solidaridad

1 En octubre de 1973 la Iglesia católica, la Iglesia luterana, la Iglesia metodista, la Iglesia ortodoxa y la comunidad judía crearon el Comité de Cooperación para la Paz, a fin de prestar servicios de defensa legal y atención social. Al cierre de esta iniciativa, en 1976 el arzobispo de Santiago creó la Vicaría de la Solidaridad con esos propósitos, que duró hasta 1992. 
(desde 1976), en la Fundación de Ayuda Social de las Iglesias Cristianas (desde 1977) y en la Corporación de Derechos del Pueblo (desde 1980).

Estos equipos de atención fueron la primera instancia en la que se constataron las graves consecuencias de la represión política sobre las personas y sus familias. Los consultantes eran personas que habían sido secuestradas y torturadas; familiares de ejecutados políticos, personas que habían sufrido condenas y encarcelamiento por varios años y salían al exilio, conmutando la pena de cárcel por el extrañamiento (Garcés y Nicholls 2005). Consultaban también familiares de detenidos desaparecidos, y, desde 1981, consultaron también personas y familias que retornaban al país desde el exilio, mientras que muchos continuaban saliendo del país para proteger sus vidas. La mayoría de quienes consultaban tenían condiciones económicas precarias, no tenían trabajo y, con frecuencia, presentaban enfermedades de diverso tipo que, muchas veces, eran secuelas de la tortura y del confinamiento en condiciones extremadamente insalubres. Los encuadres del trabajo de atención psicosocial eran flexibles. Se ofrecían diversas formas de trabajo grupal y terapia ocupacional, atención familiar y consultas individuales, y, según las necesidades, se proporcionaba atención médica y psiquiátrica en los casos que la requerían. Frente a situaciones de crisis aguda o de emergencia la respuesta era una atención médicopsiquiátrica, indicándose algunos medicamentos o una intervención psicoterapéutica de tipo breve, dentro de los enfoques teóricos y clínicos predominantes en el país en ese momento, sin mayores diferencias teóricas o prácticas entre los equipos de salud mental existentes. ${ }^{2}$

El enfoque de trabajo de los equipos terapéuticos de los organismos de Derechos Humanos fue evolucionando a lo largo de los años. Hubo intercambios con grupos de otros países, y en Santiago, una coordinación eficaz entre los equipos de diversas instituciones. El trabajo en las regiones se empezó a desarrollar, con muchas limitaciones, a mediados de la década de 1980, debido principalmente al riesgo de sufrir represión por parte de las autoridades. Sin embargo, hacia finales de la dictadura se habían creado equipos de salud mental en cinco regiones, sostenidos por algunos profesionales apoyados por organismos de la Iglesia católica o la Iglesia metodista, según las regiones. La orientación psicoterapéutica de los equipos de salud mental surgió desde una

2 Una investigación realizada entre 1989 y 1992 descubrió que todos los grupos de salud mental que atendían víctimas tenían un enfoque semejante (Agger y Jensen 1996). posición de indagación y búsqueda, una actitud crítica frente a los instrumentos clásicos de diagnóstico, con una clara perspectiva dinámica, en la cual la comunicación y el vínculo, la simbolización y la sintomatología se ubicaban en un contexto social y político real. El equipo del Programa Médico Psiquiátrico de la Fundación de Ayuda Social de las Iglesias Cristianas (FASIC) fue el más completo y numeroso de profesionales de salud mental durante casi 10 años (1977-1987), y estuvo formado en sus primeros cinco años solamente por mujeres. Tuvo integrantes que tenían formación psicoanalítica, y otras tenían formación médico-psiquiátrica; algunas se habían formado en terapia familiar sistémica, y otras, en psicología social. Esta combinación permitió una gama muy amplia de posibilidades para los tratamientos que ofrecían, pero también una discusión permanente entre visiones diferentes que enriquecieron la manera de analizar las situaciones y conceptualizar el padecimiento de los pacientes. El equipo dedicó tiempo a lecturas inspiradoras de diversos autores que habían reflexionado sobre su práctica profesional desde experiencias que podrían considerarse análogas. Entre ellos cabe destacar a Carlos Castilla del Pino (1972 y 1974), quien desarrolló la mayor parte de su práctica clínica durante el franquismo en España, aunque nunca se refirió expresamente a la relación política específica. También se tuvieron muy en cuenta algunos autores argentinos, como José Bléger (1977), Armando Bauleo (1969 y 1971) y, especialmente, Marie Langer (1981 y 1987) y un grupo de psicólogos latinoamericanos en el exilio, en México, quienes fueron consejeros a distancia del equipo de FASIC.

La lectura de diversos autores hizo parte de la formación de enfoques y criterios comunes en el equipo, buscando comprender mejor los conceptos asociados a trauma, experiencias traumáticas y procesos terapéuticos. Entre ellos, Franz Fanon, autor de Los condenados de la Tierra, prologado por Jean-Paul Sartre, contribuyó a una visión que integraba el análisis de experiencias políticas diversas al esfuerzo de teorizar las consecuencias de la violencia y la tortura. ${ }^{3}$ Un lugar relevante tuvo la revisión de los escritos de Bruno Bettelheim (1973 y 1982). La descripción de su experiencia como prisionero en un campo de concentración y su conceptualización de las "situaciones límites" como experiencias vitales asociadas a la percepción de un peligro de muerte dentro de un contexto amenazador e ineludible fueron un marco de referencia importante. En la época estaba disponible

3 Ver http://autonomiayemancipacion.org/Biblioteca/D-4/Los\%20condenados\%20de\%20la\%20Tierra\%20-\%20Fanon.pdf 
una literatura variada sobre las experiencias vinculadas al Holocausto, que tenían alguna relación, a pesar de sus diferencias, con los problemas de los consultantes. Esos documentos y los otros escritos mencionados tuvieron como función incitar la reflexión y la construcción de un enfoque propio que respondiera al contexto político y a los padecimientos de las víctimas.

El trabajo se realizaba en un marco institucional limitado por las riesgosas condiciones de la época. Por esta razón, las modalidades de trabajo fueron inicialmente intervenciones en crisis, que se fueron transformando progresivamente en modalidades flexibles y abiertas a las necesidades de los y las consultantes, sin las restricciones de un trabajo acotado en el tiempo por las condiciones institucionales. ${ }^{4}$

Aprendimos que la asistencia psicológica debía sustentarse en un reconocimiento del doble carácter de las consecuencias de las violaciones a los Derechos Humanos en la vida de las personas. Por una parte, se trataba de efectos emocionales y materiales, expresados en dolores, enfermedades, sufrimientos y conflictos interpersonales. Por otra, se trataba de fenómenos de origen y significación política vinculados con sus proyectos vitales, sociales, y su participación política. Considerábamos que era fundamental la construcción de un vínculo de trabajo, que denominamos comprometido, para diferenciarlo de cualquier otro vínculo terapéutico o social. Implicaba una actitud éticamente no neutral frente al padecimiento del paciente, entendiendo que el trastorno o la alteración que presentaba era el resultado de una agresión infligida deliberadamente por sus ideas o actuaciones políticas por parte de agentes del Estado (Lira y Weinstein 1984). El vínculo terapéutico comprometido implicaba facilitar y restablecer la capacidad de confiar, a través de la construcción de una relación real. La comunicación estaba centrada en los hechos sufridos por las personas, que -a pesar de su carácter abrumador, atemorizador o doloroso, y de ser parte de una realidad socialmente negada- podían ser reconstituidos y contenidos en el espacio privado de la relación terapéutica. Este modo de trabajar implicaba confirmar la experiencia vivida como un hecho realmente sucedido. Esta función fue retomada, en cierta forma, por las comisiones de la verdad, en las que se producía la escucha del Estado, confirmando y validando la experiencia

4 Parte del equipo que inicialmente formaba parte de FASIC constituyó el Instituto Latinoamericano de Salud Mental, una ONG que estaba compuesta únicamente por profesionales de salud mental. El equipo publicó artículos y libros acerca de su trabajo, que se incluyen en la bibliografía. vivida desde un lugar simbólico. El reconocimiento de la persona y su padecimiento en diversas instancias privadas y públicas generaba posibilidades de reparación que se conectaban y que podían complementarse, adquiriendo un potencial terapéutico relevante.

La conceptualización acerca del contexto político iba unida a la discusión acerca del trauma y las experiencias traumáticas que eran resultado de la violencia política. Las torturas, los secuestros, desapariciones y asesinatos, el exilio, la relegación, los amedrentamientos y allanamientos masivos eran entendidos como situaciones específicas potencialmente traumáticas, que atentaban contra la vida y la identidad de las personas, afectando negativamente su condición de miembros de una sociedad y su calidad de sujetos sociales activos y participativos.

La tortura, el desaparecimiento de un hijo o el asesinato del padre pueden constituirse en un trauma, como ocurre con el abuso sexual en los niños y adultos. Observamos que, en el contexto de la dictadura, las situaciones de secuestro, tortura, desaparición de un familiar u otras -una o varias, acumulativamente- presentaban sintomatologías semejantes a experiencias traumáticas de otro origen. Con frecuencia, se aplicaba el diagnóstico de estrés postraumático, al observarse la sintomatología descrita. En varios países, este diagnóstico contribuía a una decisión favorable de las autoridades para otorgar la condición de refugiado, especialmente en California, durante la década de 1980, lo que contribuyó a su aplicación frecuente para favorecer la inserción de exiliados por razones políticas que se encontraban como ilegales en Estados Unidos (Quiroga 2005). No obstante, este diagnóstico basado en los síntomas era, a nuestro juicio, insuficiente para dar cuenta de las situaciones de alteración emocional que observábamos. Un elemento adicional era la dificultad de considerar la dimensión pos. Las situaciones eran más bien acumulativas y podrían repetirse mientras se mantuviera la situación política, de manera que la experiencia no sólo podría volver a ocurrir sino que existía el temor constante ante la posibilidad de que se repitiera efectivamente. Más bien nos preguntábamos: ¿Cuál es la particularidad traumática de cada una de estas experiencias ligadas a la violencia política? Nos parecía que era preciso responder a esta pregunta de manera específica para cada caso, pues cada una de las situaciones (tortura, desaparición de un familiar) podría dar lugar a un trauma psicológico específico.

Es importante recordar que las violaciones de Derechos Humanos eran y son el resultado de decisiones tomadas por agentes políticos, que se materializan en la acción 
de unos seres humanos, que se transforman en victimarios, contra otros seres humanos, que se constituyen en víctimas. Las consecuencias en las víctimas se diagnostican identificando los síntomas y las alteraciones observados, que, aunque son semejantes a otras situaciones traumáticas, cobran sentido para la víctima, en la medida en que se enmarcan y se comprenden en el contexto político en el que ocurrieron, al mismo tiempo que se entienden en relación con el contexto de la vida y proyectos de cada persona. De este modo, la situación puede ser experimentada de formas muy diversas por un militante político, en comparación con una persona que no lo es, pero también puede haber muchas diferencias, de acuerdo con la edad, la experiencia, las creencias religiosas y la manera de ser de cada persona.

Definimos en esa época que el proceso terapéutico tenía como propósito trabajar en la reparación de las repercusiones de la violencia política sobre personas dañadas y traumatizadas que consultaban pidiendo ayuda en relación con lo que les estaba sucediendo. Lo que se intentaba era restablecer la relación del sujeto con la realidad, buscando recuperar su capacidad de vincularse con las personas y las cosas, de proyectar su quehacer y su futuro, mediante un mejor conocimiento de sí mismo y de sus propios recursos, y también mediante la ampliación de su conciencia respecto a la realidad que le tocaba vivir (Weinstein, Lira y Rojas 1987). Recuperar la salud mental implicaba retomar el curso de la vida integrando el pasado participativo, enfrentar las experiencias represivas con su horror y sus secuelas, y el presente con todas sus dificultades y contradicciones.

Esta modalidad terapéutica se hacía cargo del contexto histórico y político y buscaba promover la autonomía de la persona en todos los ámbitos de funcionamiento personal. Los objetivos se acordaban en las primeras sesiones, a partir de los motivos de consulta, y eran varios. Podían dirigirse al alivio de los síntomas, especialmente los estados de ansiedad e insomnio. Con frecuencia, el tratamiento implicaba interconsultas médicas en el equipo y alguna medicación que aliviara las reacciones agudas. La sintomatología era entendida como expresión de un conflicto vital actual en la lucha por sobrevivir y procesar las consecuencias de la agresión sufrida; por tanto, se buscaba responder a la pregunta “¿Por qué me ocurrió esto a mí?” en un contexto biográfico, político y circunstancial muy específico. En muchos casos la experiencia reciente se acumulaba en una historia vital que potenciaba su impacto y significado, que hacía necesario ampliar los objetivos iniciales del trabajo terapéutico. La historia personal y la experiencia represiva estaban ligadas desde el inicio. Sin embargo, poner fin al horror en la propia historia personal generaba deseos de olvido, que se contradecían inevitablemente con la voluntad política de no olvidar, que suele ser expresión de la resistencia de las víctimas. Esa tensión formaba parte del proceso.

Las pérdidas de vidas de personas queridas y el malogramiento de los proyectos personales tienen una dimensión irrecuperable y abrumadora en un contexto marcado por la impotencia de las víctimas ante los hechos consumados. El proceso terapéutico puede posibilitar reconocer el significado de lo vivido y rescatar lo reparable en un conjunto de experiencias vitales marcadas por lo irreparable. Asumir las pérdidas implica una compleja tarea, que supone descubrir lo destruido en uno mismo, es decir, reconocer la vivencia de muerte alojada en la propia interioridad. En este contexto, poder tramitar el duelo por todo lo perdido implica iniciar un proceso de elaboración que permita una desidentificación con lo amado perdido o muerto (Caruso 1975). Esto requiere poder diferenciar el muerto y el viviente (el que ha muerto y lo que ha muerto y la vida del sobreviviente). Dicho de otra manera, se trataba de transitar desde la posición de víctima a la de sobreviviente y ciudadano.

Estas distinciones requieren ser especificadas según la naturaleza de cada situación. En los casos de detenidos desaparecidos, cabe señalar que la pérdida era y es experimentada inicialmente como una ausencia forzosa, una separación que se teme sea definitiva, pero que se espera revertir con la aparición con vida del desaparecido. Las autoridades no se hacen cargo de la desaparición (aunque son las responsables). Los recursos de amparo ante los tribunales no tienen resultados. La indefinición y la ambigüedad de las autoridades sobre la suerte del desaparecido obligan a la familia a mantener constantes la búsqueda y la demanda ante los tribunales de justicia para que la situación se resuelva. En el caso de Chile, la mayoría de las familias todavía buscan a sus desaparecidos. Aunque el Estado ha asumido responsabilidades políticas en los hechos, no se han encontrado los restos para darles sepultura, y en muy pocos casos los responsables han contribuido a dilucidar cuál fue el destino final de los desaparecidos. Un problema adicional ha sido la identificación de los restos encontrados, que ha tomado décadas. Con el paso de los años, la búsqueda se ha hecho irrenunciable, tanto si la mueven el afecto y la lealtad familiar con el desaparecido, como si la denuncia pública y política se hace en nombre de los derechos de todos y del imperio de la ley como fundamento de la convivencia democrática. 
Durante la dictadura, en la vinculación entre contexto y efectos traumáticos de la violencia política -a juicio de los equipos psicosociales de la época-, se requería analizar algunos procesos psicosociales desencadenados por la represión política. Uno de ellos era la percepción de amenaza desde las personas y los grupos sociales. Describimos en esos momentos como amenaza política la práctica de violaciones de Derechos Humanos como política del régimen y la respuesta de miedo generalizado de amplios sectores de la sociedad. El miedo movilizaba vivencias de impotencia e indefensión ligadas a la inminencia de pérdidas y al riesgo vital, permaneciendo como una huella invisible en la interioridad de cada sujeto y en la vida social, incluso mucho tiempo después de haber cesado la amenaza directa (Lira y Castillo 1991).

La desconfianza erosionaba las relaciones sociales y diluía los esfuerzos políticos de unidad para terminar con la dictadura y construir el proceso de transición a la democracia. El final del régimen abría perspectivas de cambio, pero este último era, en muchos sentidos, una amenaza a las adaptaciones y equilibrios logrados durante el conflicto, por desajustados que ellos fueran. En cierta forma, el miedo operaba como motivación para la supervivencia y, a la vez, la adaptación a la situación, inhibiendo los recursos, las capacidades y los esfuerzos para cambiarla (Martín Baró 1990). ¿Cómo entender la tarea de reparación individual y social en un escenario político en transición o declarado en transición? ¿Cuáles eran y son los desafíos y dificultades que se presentaban y se presentan al trabajo psicológico de reparación en un contexto político en el que se mantiene la violencia?

\section{Otros temas sobre los QUe podemos ReflexionAR}

Cuando iniciamos el trabajo de atención clínica y terapéutica carecíamos de conocimientos eficaces y de la experiencia suficiente para abordar las consecuencias individuales y colectivas de la violencia que existía en la sociedad y que se concretizaba en las diversas formas de represión política, especialmente en la tortura. Para cada persona la experiencia de violencia y destrucción, con sus consecuencias de pérdidas, duelos y rabias, era particular. Era su propia identidad individual la que había sido amenazada y fragmentada, pero esos efectos subjetivos propios eran consecuencia del proceso político del país y se podían entender en relación con la actuación de cada persona en ese proceso. Sin embargo, el paso del tiempo, con su bagaje de nuevas experiencias, modificaba la percepción del pasado, del proyecto personal, de la participación política, y, por tanto, las signi- ficaciones ya no eran las mismas. Rastrear los cambios de esos significados era parte del trabajo terapéutico, y sigue siéndolo hasta el presente.

Durante el período de mayor represión y de mayor silencio social (1973-1983), el trabajo terapéutico se iniciaba, casi siempre, con la reconstitución de la experiencia represiva vivida, expresada como un testimonio que posibilitaba algún grado de elaboración emocional, permitiendo, a su vez, vincularla al contexto de la biografía y de la experiencia vital de la persona que consultaba (Lira y Weinstein 1984). Al inicio, el testimonio fue una técnica terapéutica relevante. El relato era grabado y transcrito. El producto de este trabajo se leía y repasaba en las sesiones, se comentaba y revisaba, y se convertía en un texto que pertenecía a la persona consultante, quien podía usarlo, principalmente, en la denuncia de lo que le había sucedido, y, en muchos casos, posibilitaba otras formas de comunicación con su propia familia acerca de lo que había vivido. Cada texto era un fragmento de la vida de una persona, que, a su vez, formaba parte de la vida nacional. Se centraba en la experiencia de represión política, confirmándola como un hecho cierto, en un contexto social de negación generalizada (Cienfuegos y Monelli 1983). El testimonio permitía dirigir la rabia y los sentimientos agresivos a través de la denuncia de las violaciones de Derechos Humanos, acción que estaba ligada a la expectativa de contribuir a ponerles fin y a terminar con la dictadura. Esa dimensión de denuncia fue desarrollada por los propios consultantes mucho más allá del espacio terapéutico; ${ }^{5}$ posibilitaba orientar también un conjunto de experiencias muy destructivas, especialmente el padecimiento de torturas, hacia un espacio político y social que las resignificaba. Cuando la mayoría de la sociedad chilena empezó a expresarse abiertamente contra la dictadura, aproximadamente desde 1983, a través de las protestas nacionales, el testimonio dejó de tener la importancia terapéutica que tuvo en los años anteriores.

Otro aspecto relevante era lo que ocurría con los propios terapeutas. Las motivaciones para involucrarse en esa tarea por parte de trabajadores sociales, psicólogos, terapeutas, abogados y otros profesionales en los organismos de Derechos Humanos se fundaban en valores y en opciones vinculadas a sus compromisos históricos

5 Las denuncias eran enviadas a los relatores especiales del caso de Chile de la Comisión de Derechos Humanos de Naciones Unidas. La votación anual en la Asamblea General, que condenaba las violaciones de Derechos Humanos en Chile, era percibida como un logro personal y como el resultado de los testimonios enviados. Ver también http:// www.umatic.cl/histch7.html (último acceso, 21 de junio de 2010). 
y políticos. La no neutralidad ética frente a la violencia y la violación de los derechos de las personas era un elemento distintivo del vínculo terapéutico y de la actitud de los profesionales, subrayando la imposibilidad de asumir una posición neutral frente a la represión política. Los y las terapeutas estábamos involucrados con nuestras capacidades profesionales y nuestras emociones, y también como ciudadanas y ciudadanos. Las condiciones de amenaza en las que se vivía eran actualizadas cotidianamente, apareciendo en las sesiones, lo que implicaba trabajar muchas veces con un contenido muy angustioso que provenía de la amenaza de la realidad externa, y que podía afectar a pacientes y terapeutas de una manera muy concreta. La percepción de la amenaza podía desencadenar también ansiedades ligadas a la propia biografía. Sin embargo, las angustias no se registraban expresamente de manera que permitieran procurarles contención, y no se habían previsto espacios de elaboración en las instancias institucionales. Probablemente, el carácter en extremo amenazante de la situación política y la relevancia atribuida a las motivaciones éticas de los terapeutas fomentaban una actitud de omnipotencia frente a este trabajo, como un factor cualitativamente relevante, que facilitaba negar la angustia inherente a la vida propia y al trabajo cotidiano. Esta actitud era observable también en la mayoría de los trabajadores de Derechos Humanos (Lira 1995).

Las condiciones de trabajo de los organismos de Derechos Humanos no permitían dar importancia al desgaste emocional de los profesionales ni tampoco al impacto de la escucha de historias terribles como consecuencia de trabajar con víctimas cuyas experiencias eran devastadoras. Las dificultades y la impotencia experimentadas podían ser atribuidas a las condiciones políticas y, más tardíamente, a las insuficiencias de las estructuras institucionales. La reacción espontánea frente a las dificultades tendía a ponerlas en el afuera, lo que posibilitaba unir al equipo y habilitarlo para expulsar lo contradictorio o conflictivo como no perteneciente al grupo, potenciando a su vez la omnipotencia como reacción que intentaba superar la impotencia que embargaba al equipo. Más de alguna vez, el equipo terapéutico se enfrentó a situaciones de amenaza. La reacción grupal implicó priorizar la protección de los consultantes, sin considerar los efectos en el equipo.

En este contexto específico, uno de los recursos desarrollados para enfrentar la angustia generada por este trabajo fue el intento de sistematizar y conceptualizar la experiencia de trabajo y denunciar lo que estaba sucediendo a las víctimas y a sus familias en instancias sociales, académicas e internacionales. Se escribieron trabajos, artículos y diversos documentos explicitando las consecuencias individuales y colectivas de la represión política y de situaciones traumáticas específicas como la tortura o la desaparición de personas (Lira y Castillo 1986; Lira, Weinstein y Kovalskys 1987). Al formular estas ideas, al situar estas experiencias en un marco conceptual, se ponía un límite a la angustia experimentada. Mediante las palabras, se dio un orden a la realidad aterrorizadora vivida por las víctimas y las terapeutas, posibilitando el encauzamiento de las ansiedades y confusiones generadas por este trabajo. Sin embargo, los escritos hacían referencia solamente a los pacientes. No se describían las dificultades de las y los terapeutas. El impacto transferencial y contratransferencial de la violencia, la agresión y la angustia que los pacientes llevaban a las sesiones estaba ausente. Al final de la dictadura se inició un conjunto de actividades de autocuidado y supervisión permanente, que permitieron, precisamente, identificar, procesar y asumir algunas de las dificultades descritas con anterioridad.

Esta revisión breve y sintética de lo que aprendimos requiere mencionar, además, los aspectos éticos incluidos en el trabajo terapéutico y psicosocial con víctimas de violaciones de Derechos Humanos que es necesario explicitar. En cada intervención se requiere garantizar el cuidado y bienestar de las personas y el respeto por su dignidad. Cada iniciativa de trabajo sobre los dolores y las pérdidas de las personas debe enmarcarse en esos principios, excluyendo todo aquello que puede volver a causar daño y dolor. Ello implica establecer los resguardos necesarios, a fin de que quienes implementen procesos terapéuticos o psicosociales sean competentes para ello, estén conscientes de sus límites y puedan pedir ayuda, si la necesitan. En el mismo sentido, se debe procurar el cuidado y autocuidado de quienes forman parte de los equipos, para evitar el desgaste emocional y otros efectos negativos asociados a este tipo de trabajo. Las consideraciones éticas mencionadas deben establecerse también para quienes realizan trabajos de investigación con víctimas, especialmente referidos a procesos de recuperación de memorias que se basan en testimonios. Se requiere garantizar que esos procedimientos no causarán daño y que respetarán la privacidad y el dolor de las personas. Es necesario, además, que quienes son entrevistados otorguen su consentimiento de ser grabados y registrados audiovisualmente, y se debe explicitar el uso posterior del material recogido, estableciendo con claridad las condiciones de confidencialidad, el almacenamiento, la propiedad de los datos y las condiciones de privacidad que se respetarán, en caso de eventuales publicaciones o difusión de las entrevistas. 


\section{LA MEMORIA DE EXPERIENCIAS POLÍTICAS TRAUMÁTICAS}

El saber sobre lo traumático que hemos aprendido a través de la práctica clínica, nos ha mostrado que las experiencias de amenaza vital percibidas - es decir, la toma de conciencia de una amenaza a la existencia tal como la pensamos e imaginamos- alteran el funcionamiento de la memoria generando, en muchos casos, un olvido masivo que encapsula la totalidad de la experiencia y que se hace inaccesible a la conciencia, o que, por el contrario, se manifiesta como una amplificación de la memoria haciendo literalmente inolvidable lo vivido, en todos sus detalles y significaciones. Es decir, el recuerdo se impone, impidiendo cerrar la experiencia e invadiendo la vida del sujeto con imágenes recurrentes y angustias intolerables, que no dan tregua, ni en el sueño ni en la vigilia.

Nuestra práctica clínica mostró también que, especialmente en el tratamiento de personas traumatizadas, la catarsis -al recuperar los recuerdos reprimidos- era aliviadora e incluso podía incidir haciendo desaparecer algunos de los síntomas, pero este alivio era casi siempre transitorio. Observamos que el psiquismo se había reorganizado en función de la amenaza de muerte percibida, y no bastaba solamente con volver al momento de la amenaza. Se hacía necesario trabajar con la experiencia de casi muerte que había vivido la persona analizando cómo esa amenaza se había inscrito en su historia, cómo esa casi muerte había cruzado sus vínculos, su trabajo, sus sueños. Por lo mismo, la función de recordar lo reprimido y lo olvidado como estrategia curativa conducía a identificar la necesidad de procesar el conjunto de la experiencia en sus distintos contextos, teniendo como eje central el trabajo de la memoria de ese pasado en función de la vida.

La imposibilidad del olvido circunscrita a ciertas experiencias traumáticas abre la pregunta sobre el proceso inverso: ¿cómo posibilitar algún tipo de olvido, cuando la experiencia del tiempo traumático se impone como un presente interminable marcado por la imposibilidad de un simple transcurrir? Tomando en consideración este otro ángulo, se entienden mejor las explicaciones populares que vinculan la memoria con la evocación de los sufrimientos, y el alivio de éstos, con el olvido y la supresión de la memoria.

Las reacciones descritas tienen claves psicobiológicas que explican la memoria forzosa o la amnesia radical, y que, en último término, se encuentran asociadas a la supervivencia. De este modo, recordar u olvidar son alternativas complejas que se estructuran de acuerdo con la percepción consciente o inconsciente del sujeto de que su propia vida depende de olvidar o recordar, pero no siempre se trata de opciones; es decir, dentro de lo que sabemos, no se presenta claramente como una alternativa que el sujeto pueda elegir. La memoria al margen de la conciencia -de ese darse cuenta que opera como continuidad permanente en lo cotidiano- puede ser vivida como un recuerdo ajeno, sin sentido para el sujeto, y se hace inútil como recurso para el alivio de su ansiedad y temor, y, por tanto, infructuoso para la supervivencia. La psicobiología de la memoria nos indica que el recordar y el olvidar son el fruto de una red de conexiones, estructuralmente análoga en todos los seres humanos, pero diversa y diferenciada en cada uno, no solamente en la selección de lo que se recuerda sino también en como se recuerda (con imágenes, olores, impresiones, emociones, detalles o sentimientos gruesos que apuntan al significado de la experiencia y que queda fijado como una condensación individual). Algunas investigaciones recientes sobre la memoria concluyen que no es una facultad única sino que lo que llamamos memoria es el resultado de diferentes sistemas que dependen de distintas estructuras cerebrales. La flexibilidad o inflexibilidad, así como su accesibilidad, dependen de la integridad de los circuitos, pero también de la existencia de daños en las estructuras cerebrales que posibilitan su funcionamiento o de las experiencias traumáticas que los han alterado (Schacter y Scarry 2001).

Se ha llegado a saber que la memoria humana es el resultado de numerosos procesos simultáneos, desde los complicados circuitos neurobiológicos que la hacen posible hasta las interpretaciones y significados posteriores sobre las experiencias que la constituyen. Varios estudios han mostrado cómo testigos diversos, presentes en el mismo acontecimiento, no lo recuerdan de modo semejante ni tampoco lo distorsionan de forma idéntica. Hay un sello individual en recordar y olvidar selectivamente. Es más, diversos estudios de psicofisiología han demostrado que ningún estímulo es recibido pasivamente por las células nerviosas y que la respuesta a la luz, al sonido o la oscuridad es fruto de la "interpretación" individual de los estímulos, sobre la base de una estructura común a la especie humana. Esa estructura funciona a partir de la experiencia pasada, codificada en las conexiones nerviosas, y pone en marcha la red de dichas conexiones modificando la nueva información. La clave de estas miles de operaciones es la vida, la supervivencia.

Desde hace siglos la "memoria" se vincula a la vida social y política señalando la necesidad social de olvidar o recordar, en beneficio de la convivencia y la reconciliación 
política. Correr el velo del olvido o dictar leyes de olvido han sido expresiones que vienen desde el siglo XIX en la historia chilena y que han formado parte del discurso político en el pasado en otras sociedades, generando la expectativa de que los grandes conflictos se resolvían decretando la obliteración de la memoria de ellos. ${ }^{6}$ Es decir, decretando el olvido o dejando que el tiempo extinguiera la memoria, asumiendo que el olvido pacificaría los ánimos y las pasiones políticas. Sin embargo, este supuesto ha demostrado sus limitaciones tanto psicológicas como políticas. Por otra parte, la memoria de las víctimas es, en muchos casos, una memoria traumática, es decir, el sufrimiento y el miedo permanecen vívidamente presentes sin que el transcurso del tiempo altere ese recuerdo, pero simultáneamente sin que ese recuerdo pueda ser integrado en el conjunto de la vida y de las relaciones sociales. La emocionalidad que tiñe esos recuerdos tiene la intensidad producida por una o muchas experiencias percibidas como amenazadoras y con riesgo de muerte, a las que se asocian pérdidas o temor a la pérdida de personas y de afectos y relaciones significativos. Las evocaciones del pasado sintetizan y condensan esas experiencias, cuyo sentido surge del sufrimiento y del dolor de las pérdidas, pero también de las resistencias ante la represión y las amenazas y de las lealtades construidas con personas y grupos sociales en estos procesos y en el curso de la vida. La posibilidad colectiva de resolver ese pasado entretejido de experiencias personales y políticas implica reconocerlo como un asunto que no es únicamente privado y propio de las biografías e historias individuales sino que concierne también al ámbito social y público, y que puede ser resignificado en los rituales del reconocimiento social, en los procesos judiciales y en las medidas de reparación. Dicho de otra forma, el pasado compartido socialmente nunca deja de tener una dimensión privada y personal, pero cuando los mismos hechos sociales y políticos han modelado un conjunto de experiencias traumáticas para miles de personas, se construye un espacio común que marca las relaciones sociales y requiere ser elaborado en los ámbitos colectivo y personal.

La memoria colectiva de una nación se compone de memorias diversas y contradictorias, que intentarán prevalecer unas sobre otras después del conflicto (González 1996). La batalla de las memorias se apoya actualmente en la tecnología de las comunicaciones ampliando sus

6 El Edicto de Nantes, que estableció la tolerancia religiosa en Francia en 1598, empezaba señalando que la memoria de todo lo acontecido entre las partes desde el inicio del mes de marzo de 1585, "permanecerá borrada y extinguida, como cosa no sucedida". Ver http://huguenotsweb.free.fr/histoire/edit_nantes.htm alcances y tejiendo redes en diversos ámbitos, asegurando formas de registro y de interpretación que se despliegan casi sin posibilidades de control y censura en internet. A diferencia de otras épocas, estas posibilidades han modificado los alcances de la expresión de las víctimas y del registro de su voz en la historia, haciendo una apelación ética y política en las sociedades de las que forman parte sobre las consecuencias de la violencia sobre sus vidas (Stern 2004 y 2006).

Como se ha dicho en distintos momentos y desde distintos enfoques teóricos y disciplinarios, la aseveración de los testigos constituye el material básico para una reconstrucción de lo "sucedido", ya se trate de la historia de una familia, de un pueblo o de una nación, especialmente cuando sus testimonios son los únicos registros de hechos oprobiosos que han afectado a comunidades en conflicto. Esa verdad no existiría sin su palabra. En tiempos recientes, en muchos países, esos testigos han sido objeto de intentos sistemáticos de eliminación, tergiversación y suplantación de su palabra, mediante la negación social, la distorsión producida por la publicidad oficial y la descalificación de las palabras de las víctimas, considerándolas mentiras, agresiones al régimen en el poder o distorsiones que serían resultado de sus trastornos psicológicos. ${ }^{7} \mathrm{Al}$ mismo tiempo, las atrocidades cometidas han sido de tal magnitud que las campañas destinadas a poner en duda la palabra de las víctimas y de los testigos suelen tener resonancia en distintos sectores, y hasta hoy hay quienes no pueden creer que aquello efectivamente ocurrió. Esa visión se corresponde casi siempre con aquellos que se identificaron con las medidas represivas y las apoyaron considerándolas necesarias en función de la salvación de la patria. Sin embargo, la convergencia de los relatos de diversos testigos y la calidad de testimonios judiciales de muchos de ellos han contribuido a la credibilidad de lo sucedido a cientos de miles de personas, y también los testimonios recogidos en las comisiones de la verdad han confirmado que los hechos sucedieron y afectaron a personas concretas, con nombre y apellido.

Casi siempre, los hechos de violencia política que han generado muertes han dado origen a conmemoraciones, memoriales, sitios de memoria y diversas formas de memoria política iniciados por los familiares de los muertos o por miembros de las comunidades afectadas.

\footnotetext{
7 Todorov (2000) advirtió sobre la supresión de la memoria como una acción política realizada en diversas culturas ante los conflictos como una forma de instalar una visión del pasado a favor de los vencedores. Entre ellos, los conquistadores españoles que destruyeron los vestigios de la antigua grandeza de los vencidos.
} 
El pasado ha sido fechado, recordado y conmemorado para no olvidar (a los muertos, lo vivido, las pérdidas, el miedo...). Los sobrevivientes, los familiares de las víctimas y sus amigos y personas cercanas declaran como postura ética (y política) no olvidar, invistiendo a la memoria de una fuerza política y cultural que se asocia con frecuencia al recuerdo de las víctimas, a la búsqueda de justicia, a la lucha por la paz, a la construcción y consolidación democráticas. La resistencia contra el olvido basada en el vínculo personal con los muertos y desaparecidos suele coexistir con una resistencia basada en la fidelidad y adhesión a sus creencias, ideas y valores y proyectos políticos. Este vínculo se traduce en una lealtad profunda que suele ser el motor de memorias militantes, que buscan trascender más allá de la represión y de la muerte. En algunos casos, expresan una dimensión del proceso de elaboración del duelo de las personas y familias, $y$, a veces, también surgen en los grupos políticos de los cuales formaron parte, como una deuda moral con aquellos que murieron en la lucha. Esas memorias mantienen el sentido de la causa por la que esas personas perdieron la vida y casi siempre coinciden en afirmar que se requiere recordar para asegurar que nunca más vuelvan a ocurrir tanta muerte, tanto dolor y miedo, tantas pérdidas.

La expresión nunca más se repite como un exorcismo y se asocia también a la expresión recordar para no repetir, afirmación familiar al saber psicoanalítico, que fundamenta la urgencia de examinar el pasado y reflexionar sobre él para proponer cambios en aquello que puede reproducir y activar el conflicto; sugiere recuperar la memoria sobre el pasado conflictivo y sus consecuencias, esperando que la comprensión del proceso y sus implicaciones pueda producir un cambio en las percepciones, en las conductas, en las emociones y, por tanto, en las relaciones sociales de la comunidad en la que se produjo la violencia. Pareciera existir la expectativa de que el conocimiento de la violencia represiva y sus consecuencias generaría una reacción de indignación moral ante la crueldad, y que ése sería el motor de una decisión política y moral de no repetir, de un nunca más, haciendo una analogía sugerente, aunque a veces excesiva, con los procesos psíquicos individuales. ${ }^{8}$

8 Asociación Psicoanalítica Argentina (1986). Este documento, publicado poco después del final de la dictadura militar, constituye una contribución para pensar las políticas de la transición y la memoria.

\section{EL DEBer De MEMORIA Y LA MEMORIA COMO UN DERECHO}

La memoria en el marco de políticas oficiales de memoria y de conmemoraciones forma parte del esfuerzo de las autoridades por establecer nuevas condiciones de convivencia política que reconozcan los agravios y busquen reparar a las víctimas. Hacen parte también de la memoria surgida desde las emociones y significados que tienen para las víctimas, las familias o una comunidad determinados sucesos o acontecimientos, que pueden ser reconocidos simultáneamente como hechos históricos de la nación y, a la vez, como sucesos y memorias de una comunidad particular. Casi siempre, los hechos se refieren a violencia y muerte, y se suelen recordar, casi únicamente, como agravios y pérdidas.

En la trayectoria de los familiares de las víctimas (denuncia, manifestaciones públicas, acciones judiciales) la memoria de lo sucedido surge desde la lealtad con las víctimas, asumida como un deber moral. Se trata de los familiares que buscan a sus desaparecidos, o que exigen los restos de sus familiares asesinados, o que denuncian las torturas de sus familiares y luchan por su liberación. Las acciones son una expresión del vínculo con la víctima y, al mismo tiempo, afirman las propias convicciones y valores, el sentido de las luchas, el costo de las pérdidas y la necesidad de trascender el momento amargo de la muerte, la incertidumbre y el dolor. Esta actitud ha sido descrita como el deber de memoria. El deber de memoria se funda en la lealtad y en los afectos con las víctimas, pero es también expresión de una responsabilidad social hacia la comunidad humana global, publicitando el conocimiento de esa violencia y sus efectos, y convocando a que ésta nunca más se repita. Estos propósitos se encuentran en las iniciativas de memorialización y sitios de memoria en varios países. El deber de memoria fue explicitado en los escritos de Primo Levi, sobreviviente del genocidio nazi, interpretando ese deber en función de las lealtades de los vivos con sus muertos (Levi 2006); se inscribe en una visión valorativa de las relaciones sociales basada en el respeto al otro, en su individualidad y diversidad, y en la esperanza de que la memoria contribuirá a erradicar la crueldad y el abuso por motivos políticos.

Esta visión se manifiesta principalmente en las acciones en relación con las víctimas, en la búsqueda de los detenidos desaparecidos, en la conmemoración de su ausencia, en las acciones públicas, hasta lograr identificar sus restos y conocer su destino final. Los procesos de memoria surgidos desde los vínculos con las víctimas 
han existido a lo largo y ancho del planeta; su persistencia en el tiempo surge desde la fuerza de su legitimidad afectiva y moral, tanto en América Latina como en otras latitudes. Así ha ocurrido con los familiares de muertos y desaparecidos durante de la Guerra Civil española y durante el franquismo, con familiares de los desaparecidos de la antigua Yugoslavia o del estalinismo (Merridale 2000).

La construcción de una memoria democrática, de un proceso de memoria basado en la reconstrucción de la historia y la memoria de la resistencia política a la opresión, y en la construcción democrática, funda su legitimidad en un eje complementario del anterior, puesto que las historias individuales y los testimonios de las víctimas definen el sentido ético de la memoria política, tal como se ha analizado hasta el momento. La propuesta conocida como Memorial Democrático de Cataluña es una expresión concreta de esta visión. Se trata de construir en España una memoria sobre un pasado conflictivo, que incluye la República, la Guerra Civil, la dictadura de Francisco Franco, la transición y la democracia, tropezando con amnistías y amnesias políticas en diversos momentos de los últimos 70 años.

La propuesta catalana afirma que la memoria es un derecho. A partir de esa visión (y convicción), diversos grupos, desde la sociedad civil, se propusieron fundar una política pública sobre la memoria. Argumentando el derecho a la memoria política han apelado a la expresión de los valores de la lucha democrática como patrimonio cultural para la democracia y la gobernabilidad. La propuesta del Memorial Democrático de Cataluña se funda en la convicción de que la convivencia democrática no se ve favorecida por la amnesia política de un pasado violento, sino al contrario. Se requiere, señalan, un diálogo permanente entre la disciplina histórica y el testimonio de la vivencia, entre el conocimiento científico y la memoria:

El Memorial Democrático se ha concebido como un observatorio de los valores de la democracia y un motor de iniciativas destinadas a mantener la memoria histórica. Como una herramienta del gobierno para transmitir a las nuevas generaciones los fundamentos históricos de nuestro sistema de libertades y garantías sociales. [...] La finalidad última de una política pública de la memoria democrática es proclamar solemnemente la vigencia de los valores democráticos como fundamento del modelo de organización y de convivencia de la sociedad catalana actual. Es, también, proclamar la voluntad de proyectar estos valores hacia el futuro. A esta función de afirmación, el Memorial le añade la de desagravio y homenaje a todas las víctimas directas o indirectas de la lucha por la democracia, mínimo gesto que merecen como depositarias de una memoria silenciada, si no negada.

Proclamar y rememorar -conmemorar en definitivason acciones que confieren al Memorial naturaleza de monumento en el sentido más radical del término: aquella obra humana edificada con la finalidad precisa de conservar vigente, en la conciencia de las generaciones futuras, el recuerdo de un acontecimiento o de un proyecto de futuro, o bien de ambas cosas a la vez. ${ }^{9}$

La propuesta del Memorial Democrático de Cataluña afirma, además, que las nuevas instituciones democráticas requieren de una condena política formal de los regímenes dictatoriales anteriores, para legitimar institucionalmente una política oficial de recuperación de la memoria democrática.

\section{A MODO DE CONCLUSIONES}

Es importante recordar que las víctimas y sus familiares han luchado en decenas de países, durante décadas, buscando verdad y justicia, como dijimos al comienzo. El esfuerzo inicial era lograr que se reconociera la detención y luego la desaparición de sus familiares como hechos sucedidos efectivamente, enfrentando la negación oficial, incluso a riesgo de sus vidas. Ha sido habitual que las autoridades declararan, a pesar de las evidencias en contrario, que los hechos no tuvieron lugar. El primer objetivo de las víctimas ha sido, entonces, que las autoridades y los tribunales de justicia reconocieran la existencia de los hechos que las habían afectado.

Al instalarse los gobiernos de transición de regímenes autoritarios a regímenes democráticos, las expectativas de los grupos y asociaciones de víctimas son, precisamente, que se reconozca lo que les ocurrió a ellos mismos o a sus familiares, que se reconozcan sus derechos y que se repudie, formalmente, la política de violaciones de Derechos Humanos. En muchos países la condena moral y política de los crímenes cometidos se ha expresado en las declaraciones y discursos de las autoridades que asumen el poder después del conflicto, representando a las fuerzas políticas opositoras y denunciando las violaciones de Derechos Humanos cometidas.

9 http://www.gencat.cat/generalitat/cas/govern/infocatalunya/08_infocat/04.htm (último acceso,10-12-09). 
En Chile, después del final del régimen militar, el primer gobierno de la transición estableció una Comisión Nacional de Verdad y Reconciliación destinada a identificar los casos de detenidos desaparecidos, ejecutados políticos y víctimas de violencia política (1990-1991). Trece años después se estableció una Comisión Nacional de Prisión Política y Tortura (2003-2005). ${ }^{10} \mathrm{La}$ Comisión Nacional de Verdad y Reconciliación, así como la Comisión Nacional de Prisión Política y Tortura, señalaron en sus conclusiones que las violaciones de Derechos Humanos tuvieron efectos devastadores en las víctimas y en la convivencia social de la sociedad chilena, y rechazaron moral y políticamente que desde el Estado se hubiesen diseñado políticas sistemáticas de represión política utilizando la tortura y la desaparición de personas. Sin embargo, y paradójicamente, esos informes y las voces de las víctimas se suelen cerrar en el mismo momento en que se dan a conocer, y en poco tiempo se transforman en documentos simbólicos que concentran el horror del pasado pero no logran despertar un interés memorial, precisamente por su penoso contenido, incluso entre las propias víctimas.

Esas reacciones contribuyen a que esta historia sea, haya sido y siga siendo abrumadora no sólo para las víctimas sino para grandes grupos sociales en cada sociedad, precisamente porque esas historias se congelan en el momento del horror. Por otra parte, la formulación del deseo de Nunca más respecto al pasado oprobioso es una invitación a recordar para aprender de esta experiencia en el ámbito social y político, convocando a una nueva forma de convivencia. Estos dos movimientos no parecen encontrarse. Sin embargo, uno y otro no tienen mayor relevancia y efectividad para asumir (y superar) el pasado mientras no den curso a procesos que permitan grados de elaboración de lo vivido, padecido, renegado y destruido, es decir, procesos que posibiliten formas intencionadas de elaboración emocional y moral por parte de las y los afectados que faciliten construir una memoria común, con el propósito de sanarse ellos mismos e introducir procesos que apunten a la sanación de la vida social. De este modo, memoria y reparación social, procesos terapéuticos y proceso social democrático se vinculan y entretejen.

La reparación supone los debidos procesos legales, en el marco jurídico de cada país y de sus posibili-

10 Comisión Nacional de Verdad y Reconciliación. Informe de la Comisión Nacional de Verdad y Reconciliación, tres tomos. Santiago, 1991. Ver http://www.ddhh.gov.cl/ddhh_rettig.html; Comisión Nacional de Prisión Política y Tortura. Informe de la Comisión Nacional de Prisión Política y Tortura. Edición oficial, 2005. http://www.lanacion.cl/prontus_noticias/ site/edic/home/port/torturas.html (último acceso, 12-01-10). dades políticas, aunque no se agota en ellos. Supone la construcción de una cultura democrática, fundada en el respeto intrínseco a los Derechos Humanos de cada uno, incluido el derecho a un debido proceso de los victimarios. Implica también una elaboración social del sufrimiento y de la violencia en el ámbito cultural reconociendo que esto ocurrió entre nosotros y que es lo que queremos que no vuelva a ocurrir. Cada víctima tiene derecho a que su historia y su padecimiento sean reconocidos como una injusticia y como una violación a sus derechos; que la sociedad le otorgue una reparación que incluya espacios de reflexión y elaboración en todos los niveles de contexto implicados, y que la memoria política conserve su nombre y su historia como elementos indispensables para sostener una memoria democrática que garantice el respeto y la dignidad de las personas en todo momento y circunstancia, ahora y en el próximo futuro. Cada país y cada comunidad humana son desafiados a construir la paz basada en la verdad de lo sucedido y en el reconocimiento y reparación de las víctimas, dejando atrás las fórmulas políticas que fundaron la paz en la impunidad de crímenes atroces, sembrando resentimientos y favoreciendo el resurgimiento de los odios y las venganzas y la recreación de la violencia con afanes justicieros, por ausencia de justicia.

\section{RefERENCIAS}

1. Agger, Inger y Sören Buus Jensen. 1996. Trauma y cura en situaciones de terrorismo de Estado: Derechos Humanos y salud mental en Chile bajo la dictadura militar. Santiago: Chile América - CESOC.

2. Asociación Psicoanalítica Argentina. 1986. Argentina, psicoanálisis, represión política. Buenos Aires: Ediciones Lombardi de Kargieman.

3. Bauleo, Armando. 1969. Grupo Operativo. Cuadernos de Psicología Concreta I, No. 1.

4. Bauleo, Armando. 1971. Ideología, grupo y familia. Buenos Aires: Ediciones Lombardi de Kargieman.

5. Bettelheim, Bruno. 1973. El corazón bien informado. México D.F.: Fondo de Cultura Económica.

6. Bettelheim, Bruno. 1982. Sobrevivir, el Holocausto una generación después. Barcelona: Crítica.

7. Bléger, José. 1977. Grupo de la enseñanza. Montevideo: Editorial Punto 2 - Centro de Investigación y Experimentación Pedagógica (CIEP). 
8. Caruso, Igor. 1975. La separación de los amantes. Una fenomenología de la muerte. México D.F.: Siglo XXI Editores.

9. Castilla del Pino, Carlos. 1972. Dialéctica de la persona. Dialéctica de la situación. Barcelona: Alianza Editorial.

10. Castilla del Pino, Carlos. 1974. Estudio sobre la depresión. Barcelona: Alianza Editorial.

11. Cienfuegos, Ana Julia y Cristina Monelli. 1983. The Testimony of Political Repression as a Therapeutic Instrument. American Journal of Orthopsychiatry 53: 43-51.

12. Centro de Estudios Legales y Sociales (CELS). 1989. Efectos de la impunidad en el sujeto y en el cuerpo social. En Derechos Humanos: todo es según el dolor con que se mira, ed. ILAS, 163-175. Santiago: Ediciones ILAS.

13. Comisión de Derechos Humanos (ONU). 2009. El derecho de restitución, indemnización y rehabilitación de las víctimas de violaciones graves de los Derechos Humanos y las libertades fundamentales. Resolución de la Comisión de Derechos Humanos 2003/34 http:/www.unhchr.ch/ Huridocda/Huridoca.nsf/(Symbol)/E.CN.4.RES.2003.34. Sp?Opendocument:(Recuperado el 6 de octubre de 2009).

14. Comisión Nacional de Prisión Política y Tortura. 2004. http://www.comisiontortura.cl/listado_informes.html (Recuperado el 6 de octubre de 2009).

15. Comisión Nacional de Verdad y Reconciliación. 1991. http://www.ddhh.gov.cl/ddhh_rettig.html (Recuperado el 6 de octubre de 2009).

16. Garcés, Mario y Nancy Nicholls. 2005. Para una historia de los DD. HH. en Chile: historia institucional de la Fundación de Ayuda Social de las Iglesias Cristianas (FASIC), $1975-$ 1991. Santiago: LOM.

17. González, Fernando. 1996. La guerra de las memorias. Psicoanálisis, historia e interpretación. México D.F.: UNAM Plaza y Valdés.

18. Instituto Latinoamericano de Salud Mental y Derechos Humanos (ILAS). 1989. Derechos Humanos: todo es según el dolor con que se mira. Santiago: Ediciones ILAS.

19. Instituto Latinoamericano de Salud Mental y Derechos Humanos (ILAS). 1994. Psicología y violencia política en América Latina. Santiago: América - CESOC.

20. Instituto Latinoamericano de Salud Mental y Derechos Humanos (ILAS). 1997. Reparación, Derechos Humanos y salud mental. Santiago. Chile América - CESOC.

21. Langer, Marie (Comp.). 1987. Cuestionamos. Buenos Aires: Ediciones Búsqueda.

22. Langer, Marie. 1981. Memoria, historia, y diálogo psicoanalítico. México: Folios.
23. Levi, Primo. 2006. Deber de memoria. Barcelona: Editorial Libros de Zorzal.

24. Lira, Elizabeth. 1995. The Development of Treatment Approaches for Victims of Human Rights Violations in Chile. En Beyond the Trauma. Selected Papers from the First World Conference on Traumatic Stress, eds. Rolf Kleber, Charles Figley y Berthold Gerson, 115-127. Nueva York: Plenum Press.

25. Lira, Elizabeth y Eugenia Weinstein (Eds.). 1984. Psicoterapia y represión política. México D.F.: Siglo XXI Editores.

26. Lira, Elizabeth y María Isabel Castillo. 1991. Psicología de la amenaza politica y del miedo. Santiago: Ediciones ILASCESOC.

27. Lira, Elizabeth y María Isabel Castillo. 1986. Psicología, justicia y democracia. Santiago: Instituto para el Nuevo Chile (ESIN).

28. Lira, Elizabeth, Eugenia Weinstein y Juana Kovalskys. 1987. Subjetividad y represión política: intervenciones terapéuticas. En Psicología política latinoamericana, eds. Maritza Montero e Ignacio Martin-Baró, 317-346. Caracas: Ediciones Panapo.

29. Lira, Elizabeth y Brian Loveman. 2005. Políticas de reparación. Chile: 1990-2004. Santiago: LOM - Universidad Alberto Hurtado.

30. Martín Baró, Ignacio. 1990. Psicología social de la guerra. San Salvador: UCA Editores.

31. Merridale, Catherine. 2000. Night of Stone. Death and Memory in Twentieth-Century Russia. Londres: Penguin Books.

32. Quiroga, José. 2005. Experiencia con sobrevivientes de tortura que han migrado a California. En Derechos Humanos y reparación. Una discusión pendiente, eds. Elizabeth Lira y Germán Morales, 117-130. Santiago: LOM - Universidad Alberto Hurtado.

33. Schacter, Daniel y Elaine Scarry (Eds.). 2001. Memory, Brain and Belief. Cambridge: Harvard University Press.

34. Stern, Steve. 2004. Remembering Pinochet's Chile: On the Eve of London 1998. Durham: Duke University Press.

35. Stern, Steve. 2006. Battling for Hearts and Minds: Memory Struggles in Pinochet's Chile, 1973-1988. Durham: Duke University Press.

36. Todorov, Tzvetan. 2000. Los abusos de la memoria. Barcelona: Paidós

37. Weinstein, Eugenia, Elizabeth Lira y María Eugenia Rojas. 1987. Trauma, duelo y reparación. Santiago: FASIC - Interamericana. 